\title{
POLIMERIZANDO IDEIAS: UM RECURSO PEDAGÓGICO NO ENSINO DA QUÍMICA DOS POLÍMEROS
}

\author{
Calliu Carneiro Barbosa, Caroline de Goes Sampaio, \\ Maria Cleide da Silva Barroso, InAí́ lopes Guerreiro \\ Instituto Federal de Educação, Ciência e Tecnologia do Ceará, \\ Campus de Maracanaú \\ $<$ calliubarbosa@live.com>, <carol-quimica@ hotmail.com> \\ <ccleide1971@yahoo.com.br>, <inaialopes@ hotmail.com>
}

DOI: $10.21439 /$ conexoes.v9i4.996

\begin{abstract}
Resumo. Diversos materiais podem ser ferramentas muito relevantes no que concerne o processo de ensino-aprendizagem. Os jogos, por sua vez, são uma opção pertinente para auxiliar neste processo. Nesse artigo, discutiu-se aspectos relacionados com à teoria da aprendizagem significativa, defendida por Ausubel, através dos resultados obtidos com a utilização do jogo: "Polimerizando Ideias". Objetivou-se constatar a importância deste para melhor compreensão e assimilação dos alunos no conteúdo de Química dos Polímeros. Este trabalho trata-se de uma pesquisa-ação, realizada com alunos do terceiro ano do ensino-médio, em uma escola pública estadual, no município de Maracanaú, Ceará. A metodologia consistiu em aulas expositivas com apresentação áudio visual e experiências químicas realizadas na sala de aula, cuja abordagem pedagógica foi baseada na teoria sócio-interativista elaborada por Vygotsky. Empregaram-se também instrumentos de avaliação, questionários e textos. Os resultados observados apontaram o método utilizado como uma possibilidade de fomentar um recurso interessante em aulas ministradas para o ensino médio. Isso foi possível de ser verificado quando observado um aumento satisfatório na apropriação/construção dos conhecimentos por parte dos alunos. Esse fato se justifica principalmente ao emprego de experiências químicas pertencentes ao cotidiano e ao contexto dinâmicointerativista do jogo.
\end{abstract}

Palavras-chaves: Química. Jogos didáticos. Polímeros. Avaliação.

Abstract. The various materials can be - very important tools as regards the teaching-learning process. Games, in turn, are a relevant option to assist in this process. In this article, we discussed aspects related to the Theory of Meaningful Learning, advocated by Ausubel, through the results obtained in the project, using the game: "Polymerizing Ideas". It aimed to realize the importance of this for better understanding and assimilation of the students in the Chemistry of Polymers content. This work is an action research conducted with third year students of High School at the state school Tenente Mario Lima. The methodology consisted of lectures with slide show and chemical experiments in the classroom, whose pedagogical approach was based on society-interativist theory developed by Vygotsky. They are also employed evaluation tools, questionnaires and texts constructed by students. The observed results showed the method used, as an opportunity to foment a nice feature in classes taught to High School. We can see this when we certify a satisfactory increase in appropriation/construction of knowledge by students. This fact is justified mainly to the use of chemical experiments pertaining to everyday life and the dynamic-interactive context of the game.

Keywords: Chemistry. Educational games. Polymers. Evaluation. 


\section{INTRODUÇÃO}

Os conteúdos de química, vistos no ensino médio, muitas vezes desperta a apatia dos alunos, mesmo apresentando uma vasta aplicabilidade no cotidiano da humanidade. É percebida a não relação entre o conhecimento adquirido em sala de aula, com a realidade vivida por parte dos discentes. Além disso, muitas pessoas não conseguem vislumbrar a importância que essa ciência apresenta para o ingresso de muitos estudantes no ensino superior.

Alguns dos fatores citados, que referenciam a falta de interesse dos alunos, devem-se possivelmente à ausência de laboratório de ciências/química ou desuso deste espaço físico nas escolas (públicas e/ou privadas). Pode-se acrescentar também, o não incentivo dos professores e funcionários para a realização de visitas periódicas dos alunos à biblioteca, ou mesmo o fato de ambientes como este, propício para leitura e apropriação do conhecimento, não apresentarem livros favoráveis aos conteúdos vistos em sala, sejam esses didáticos ou paradidáticos. Também é observada uma enorme carência de recursos de multimídia durante as aulas. Para a maioria dos discentes, a teoria é aprendida com mais facilidade quando a prática é efetivada, seja por meio de experiências ou jogos didáticos.

Para compreender os conteúdos de química é importante enxergá-los sob uma nova ótica, onde o conhecimento científico não está configurado a um corpo de muitas teorias e procedimentos, mas como modelos teóricos sociais e produzidos a partir do conhecimento histórico (ZANON; GUERREIRO; OLIVEIRA, 2008).

Segundo Ausubel (1982), em sua teoria da aprendizagem significativa, quando o aprendiz consegue fazer relações da teoria que lhe está sendo apresentada com seus conhecimentos prévios, correlacionando os diferentes assuntos, haverá a construção de um significado, ou seja, ganho de sentido. É bem verdade a dependência de outros atributos para a geração do progresso do conhecimento em cada indivíduo, podem ser estes internos e/ou externos. "O jogo é, pois, uma atividade integradora dos aspectos internos e externos colocados como complementares" (MOREIRA, 1996, p. 55).

A mímica é a interpretação cênica de determinada situação, objeto, personalidade, dentre outros. Além disso, ela estimula a cognição, criação e interpretação dos alunos. "A proposta do jogo deve superar a estereotipia, propiciando uma aprendizagem pela criatividade. $\mathrm{O}$ acaso, que é uma característica do jogo, entra como um fator de imprevisto capaz de estimular a imaginação criativa". (MOREIRA, 1996, p. 60).

Para Vygotsky (2008), a relação entre pensamento e linguagem é estreita. A linguagem (verbal, gestual e escrita) é nosso instrumento de relação com os outros e, por isso, é importantíssima na nossa constituição, como sujeitos. Além disso, "é através da linguagem que se aprende a pensar” (RIBEIRO, 2005, p.4).

Nesse sentido, a linguagem não verbal proposta nas expressões corporais dos estudantes durante o jogo, interfere e os faz indivíduos dotados de entendimento, principalmente dos conceitos químicos. Paralelamente, à medida que se desenvolve o seu conhecimento sobre o assunto, reafirma-se a importância do mesmo, quando de certa forma força o interlocutor a criar de maneira coerente e entendível aos observadores.

Diante do quadro de realidades e desafios, o qual os professores estão expostos a enfrentar para a aprendizagem de química, nesse patamar de ensino, esse trabalho teve como objetivo contribuir para uma melhor qualidade no processo de ensino e aprendizagem dessa ciência, selecionando o tema polímeros, como foco de aprendizagem. Para isso, foi elaborado um jogo didático, com o interesse de motivar os alunos a quererem aprender mais os conteúdos relativos à química dos polímeros, promovendo um dinamismo nas aulas.

Os instrumentos da investigação foram: avaliações feitas in loco, no início e no fim da aplicação dessa atividade, com o intuito de coletar resultados, partindo-se do pressuposto que o jogo atenderia a expectativa de facilitar a aprendizagem dos alunos. Procurou-se, também, explanar a prática dinâmico-interativa arraigada no ensino de química do ensino médio (Vygotsky, 2008). As atividades apresentadas a seguir, foram realizadas com as turmas de terceiro ano do ensino médio ("B" e "C"), com cerca de 50 alunos no total, em uma escola situada no município de Maracanaú, Ceará.

\section{METODOLOGIA}

Em virtude de uma melhor organização do trabalho, foi decidido aderir a um plano de ação. Nele foram atribuídas datas, instrumentos de pesquisa, plano sistemático e qual seria a finalidade para cada um dos momentos discriminados.

Primeiro, foram levantadas algumas indagações inerentes ao projeto e as respostas que nortearam a execução de cada momento pedagógico. Entre os questionamentos, observou-se: Em quais turmas seria aplicada essa atividade? Qual o conteúdo a ser abordado? Como seriam as avaliações do conhecimento prévio e contínuo do aluno? Como o jogo seria elaborado? Qual(is) o(s) objetivo(s) do projeto? A nossa hipótese e expectativas serão atendidas?

As respostas para estes questionamentos proporcionaram a elaboração das etapas e procedimentos adotados nessa atividade, organizando a preparação 
dos recursos e ferramentas utilizadas para o ensinoaprendizagem. Inicialmente foram preparadas apresentações das aulas expositivas, bem como os planos de aula e os roteiros das experiências químicas com reagentes facilmente encontrados no cotidiano. Em seguida, o conteúdo de polímeros foi dividido em dois dias de apresentação, aos quais foram colocadas em prática as atividades presentes na Quadro 1

Quadro 1: Planejamento de atividades realizadas nos dois dias de execução do projeto.

\begin{tabular}{|c|c|}
\hline $1^{\circ}$ DIA & $2^{\circ}$ DIA \\
\hline $\begin{array}{l}\text { - Questionário sócio-econômico; } \\
\text { - Avaliação de conhecimentos } \\
\text { prévios; } \\
\text { - Aula expositiva com apresentação } \\
\text { de slides; } \\
\text { - Aplicação de experimentos de } \\
\text { química relacionados ao conteúdo } \\
\text { visto; }\end{array}$ & $\begin{array}{l}\text { - Aula expositiva com apresentação de } \\
\text { slides; } \\
\text { - Aplicação de outros experimentos de } \\
\text { química relacionados ao conteúdo visto; } \\
\text { - Aplicação do Jogo: "Polimerizando } \\
\text { Ideias"; } \\
\text { - Avaliação Final. }\end{array}$ \\
\hline
\end{tabular}

Fonte: Elaboração Própria.

Diferentes fichas avaliativas foram aplicadas nesse trabalho. Segundo Parasuraman (1991), o questionário avaliativo é tão somente um banco de questões, feito para gerar os dados necessários para se atingir os objetivos de um projeto/ação.

O primeiro instrumento de avaliação foi relativo ao perfil socioeconômico dos participantes desse trabalho. Com isso, buscou-se avaliar as condições voltadas à situação social e financeira dos alunos. Dessa forma, foi possível obter dados importantes para essa pesquisa, principalmente no que diz respeito da coleta de dados e a certificação da existência ou não da precariedade e/ou dificuldades encontradas por eles, no acesso à educação.

O segundo questionário foi aplicado antes das aulas expositivas, para isso, foram elencadas algumas perguntas da avaliação de conhecimentos prévios, de caráter subjetivo, como apresentado no Quadro 2 Para isso, buscou-se a simplicidade e objetividade em nossos questionamentos, fomentados na proposta de cunho teórico e informativo. A partir das dificuldades observadas na avaliação do segundo questionário, as aulas expositivas foram preparadas de modo a esclarecer esses e outros aspectos relacionados com a "Química dos Polímeros".

Alguns experimentos químicos, também foram realizados durante as aulas, estes fizeram menção a uma parte específica de cada momento:

- Experimento 1 - Título: Detecção de amido na maçã e em outros alimentos. Descrição: foram relacionados os conteúdos mencionados com a extração de polímeros naturais, exemplificando
Quadro 2: Questionário de avaliação dos conhecimentos prévios dos alunos sobre o tema polímeros.

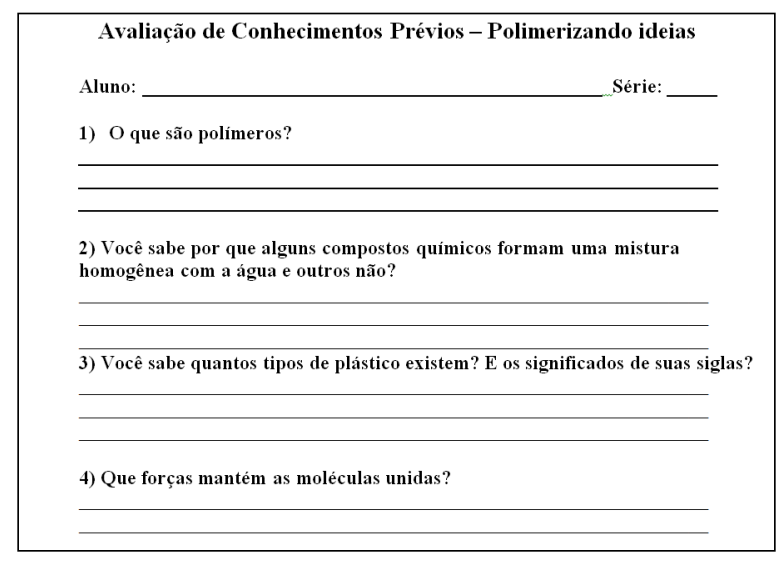

Fonte: Elaboração Própria.

o amido, presente na maçã, na batata e em outros alimentos;

- Experimento 2 - Título: Dissolvendo o poliestireno expansível (EPS) na acetona. Descrição: foi apontada a diferença de polaridade, utilizando o "EPS" como reagente, tendo em vista a composição polimérica encontrada neste material, o poliestireno, um polímero artificial;

- Experimento 3 - Título: O líquido que quer ser sólido. Descrição: essa prática envolveu a mistura de amido de milho e água. Explicou-se o fato de haver a formação de polímeros quando o líquido não-newtoniano é colocado a uma elevada pressão, possivelmente por choques mecânicos;

- Experimento 4 - Título: Fabricando cola caseira a partir da caseína (proteína do leite). Descrição: algumas proteínas são exemplos de polímeros naturais, a caseína por sua vez, propicia a fabricação de cola, já que ao ser misturada com bicarbonato de sódio, há a formação do caseinato de sódio que tem propriedades adesivas.

Reproduzindo muito bem as percepções tidas com as aplicações experimentais durante todo o projeto, o autor mencionado na citação abaixo, afirma o concreto crescimento intelectual dos alunos, quando estes são submetidos a aulas práticas. Demonstrando a necessidade de determinados conhecimentos adquiridos em sala de aula, para a compreensão de eventos, ou mesmo fatos corriqueiros da realidade.

É inquestionável que o aprendizado de química é muito melhor quando, além das aulas expositivas, os alu- 
nos têm a oportunidade de praticarem, concretamente, os conceitos apreendidos. O interesse dos alunos é despertado e o aproveitamento das aulas expositivas torna-se mais acentuado sempre que o assunto em pauta possa ser desenvolvido na experimentação (GUERREIRO et al. 2012 p. 152).

Atrelando a teoria e a prática, as aulas expositivas atraíram a atenção dos alunos, dando um maior aproveitamento daquilo que estava sendo repassado. Através da experimentação, os alunos puderam constatar a aplicabilidade desses polímeros em seu cotidiano e conhecer sobre a importância de cada um deles.

$\mathrm{Na}$ finalização desta etapa, trabalhou-se o espírito de indagação e reforço, para explicar os fenômenos observados e tirar de cada procedimento as conclusões individuais e grupais, muito embora existisse uma limitação devido aos direcionamentos propostos, delimitados pela capacidade de abstração e a diferença entre os conhecimentos teóricos.

O jogo foi pensado para ser aplicado por último com os alunos, em uma das turmas escolhidas, sendo esta avaliada logo após o término da brincadeira. A avaliação consistiu em um exercício contendo questões nos padrões do Exame Nacional do Ensino Médio (ENEM), seguindo as competências desta prova.

Contextualizando e instigando os estudantes a fazerem uma reflexão dos textos lidos e do que foi aprofundado em sala de aula, este recurso foi colocado após as aulas expositivas, mediante o embasamento adquirido, motivando os discentes a responderem, agora com mais propriedade e certeza, as perguntas feitas, durante e após o jogo, como afirma Moreira, (1996).

O jogo também revela uma característica transformadora intrínseca, pois quanto melhor a capacidade do indivíduo para jogar, mais próximo está ele da saúde mental. [...] A educação tradicional evita o jogo, porque não se preocupa com a auto-expressão; o que vale é o atendimento a regras preestabelecidas que devem apenas ser cumpridas ou no máximo melhoradas em um caminho previamente traçado (MOREIRA 1996 p. 53).

Com base nessa citação, na perspectiva da educação tradicional, o jogo não aparece como uma ferramenta bem aceita, pois nesta tipologia de educação, ferramentas lúdicas de aprendizagem se faziam desnecessárias. Erroneamente, os professores e detentores do conhecimento, estavam preocupados com o método a ser seguido, e não com as alternativas desempenhadas para a eficácia deste método.

Mesmo hoje, a não utilização, ou mesmo a falta de recursos lúdicos responsáveis pelo desenvolvimento psicológico, intelectual e cognitivo do indivíduo, muitas vezes põe em cheque a construção e modificação dos conhecimentos adquiridos, a partir da subjetivação, não promovendo um paralelo das experiências vividas e os conhecimentos anteriores.

\subsection{Confecção e aplicação do jogo}

A criação do tabuleiro foi feita mediante a aquisição de materiais de fácil acesso como: cartolinas coloridas, pincéis, cola, tesoura, etc. E sua inspiração veio de um jogo bastante conhecido, o qual faz uso de mímicas e desenhos.

Na Figura 1, é possível observar o jogo: "Polimerizando ideias", as peças envolvidas nele e como o mesmo se apresentou para os alunos. Tanto as peças como o tabuleiro, estão bem demarcados com suas respectivas numerações, símbolos e ordens.

É possível observar também, dois dados enumerados, um para o avanço de casas e o outro para a escolha dos membros que representariam a equipe, este último também utilizado para delegar de quem seria a vez de jogar.

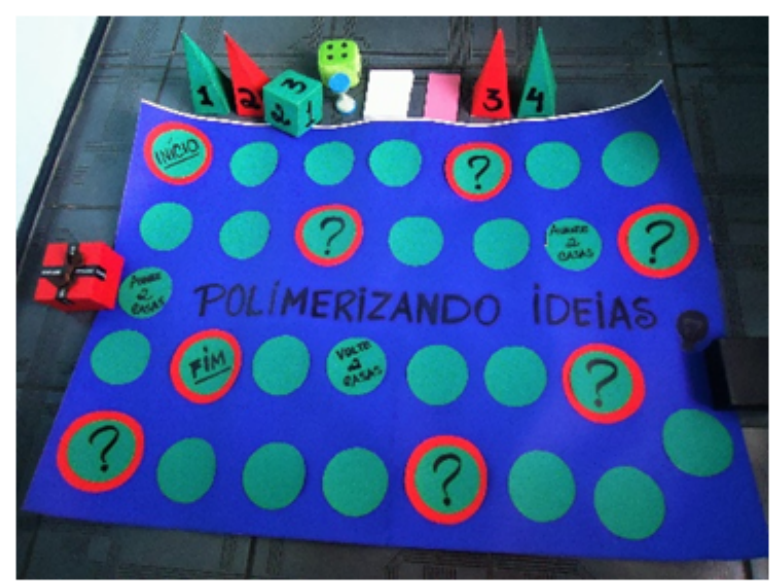

Figura 1: Jogo: Polimerizando Ideias. Fonte: Elaboração Própria.

Na Figura 2, está exposta a divisão dos grupos durante as atividades, segundo Zanon, Guerreiro e Oliveira (2008). No processo de escolha dos membros de cada equipe, podem ser distribuídos números de um a quatro, os quais determinam onde cada integrante ficará.

Polimerizando Ideias, foi concebido para ser aplicado com alunos do ensino médio, na maioria das vezes do $3^{\circ}$ ano, ou no momento em que o professor decidir utilizar, de acordo com o cronograma letivo. Foi acrescentada ainda, uma característica fundamental, a ajuda mútua entre os membros de um mesmo grupo a vencer, reiterando a "polimerização de ideias".

Além da construção de regras para o jogo, foram elaboradas trinta perguntas, trinta respostas e quatro mí- 


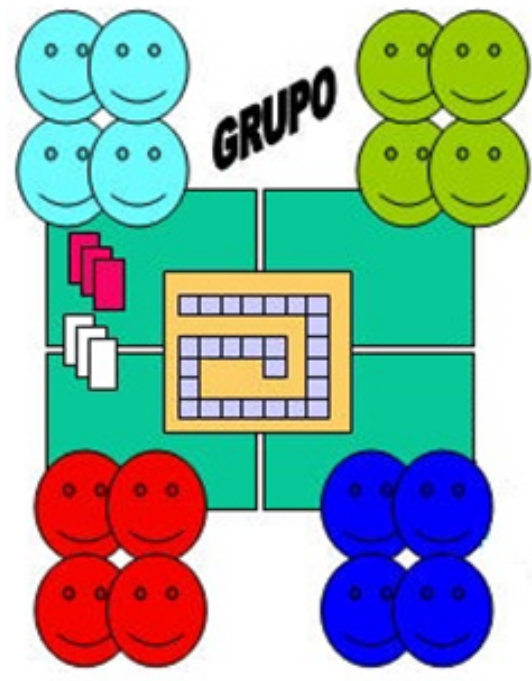

Figura 2: Divisão dos grupos. Fonte: Figura retirada de Zanon, Guerreiro e Oliveira (2008), adaptada.

micas, em formato de cartas, cuja numeração é colocada antes de cada questionamento, põe ordem no que diz respeito ao grau de dificuldade. A questão sendo classificada como: "difícil", elencada previamente pelo professor, faria o grupo avançar duas casas a mais do número apresentado no dado. Essa regra só estaria valendo, se o mesmo tivesse acertado a pergunta ou mímica proposta.

A Figura 1, permite observar que o jogo apresenta três tipos de "casa": A primeira e a mais simples, não possui absolutamente nada escrito, o que configura apenas uma pergunta. No segundo tipo, temos pontos de interrogação, encontrados no tabuleiro, onde ao parar sobre eles com o "pião", os mesmos gesticulariam uma mímica.

Um dos indivíduos deveria ser escolhido para desempenhar a tarefa, enquanto que o restante dos integrantes, do mesmo grupo, apenas observaria e tentaria acertar. A pessoa com a carta cor de rosa, não poderia, em hipótese alguma revelar o seu conteúdo. Nem para os membros do seu grupo, nem para os demais, sob pena de passar a vez e consequentemente a carta para a equipe adversária.

Na possibilidade do tempo demarcado pela ampulheta (instrumento utilizado no jogo) se esgotar, o outro grupo teria a oportunidade de tentar acertar. Essa regra valeria tanto para as perguntas, quanto para as mímicas.

No terceiro tipo de "casa" notam-se ordens para avançar ou retroceder com as respectivas peças, de imediato essas regras deveriam ser cumpridas, para definição posteriormente de um grupo vencedor. "As regras dos jogos devem ser simples e o jogo se torna mais interessante à medida que os estudantes começam a criar estratégias elaboradas e se aprimoram na antecipação das jogadas". (SMOLE, 2004, p.59).

Há dois tipos de cartas com cores distintas, branca e rosa: a primeira representa as perguntas e a segunda as mímicas, respectivamente. Estas seguem o modelo abaixo demonstrado na Quadro 3

Quadro 3: Cartas do jogo.

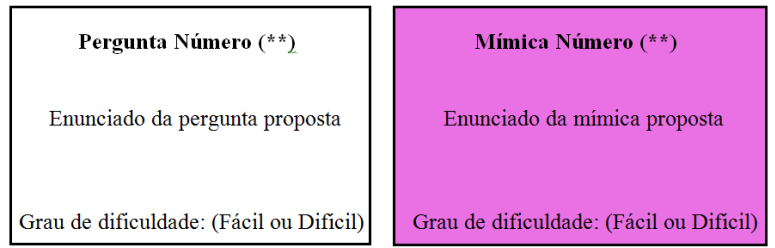

Fonte: Elaboração Própria.

Ganha o grupo que chegar primeiro ao fim do tabuleiro. Ficando a critério do professor/interventor, colocar uma premiação ou não. "A participação do professor no jogo e na brincadeira tem o objetivo de ajudá-los a perceber como podem participar da aprendizagem e da convivência em geral" (MOREIRA, 1996, p. 61).

\section{RESULTADOS E DISCUSSÕES}

Bernardelli (2005) fez uma abordagem bastante diferenciada acerca dos tipos de dificuldades encontradas na aprendizagem de química a partir da avaliação de turmas de alunos do ensino médio. Para o autor, a principal relação dessa resistência ao saber deve-se aos aspectos sócio-familiar-econômicos dos estudantes. O trabalho dele aborda uma forma para contornar, pelo menos em parte, esses problemas, onde existiria métodos de educação tutorial capazes de minimizar as dificuldades encontradas por este grupo.

Semelhante ao trabalho de Bernardelli, muitas destas dificuldades também foram encontradas nesse trabalho, que apontou uma maioria dos discentes questionados com características familiares de classe média/baixa, casas bastante numerosas e renda variando entre 1 a 5 salários mínimos. Dessa forma, é possível destacar que o acesso à materialidade e aos meios de subsistências responsáveis pelo desenvolvimento e a construção do conhecimento são minimizados, tendo em vista o desnível econômico e social atravessado por essas famílias.

Foi importante analisar esses dados de forma conjunta, fazendo uma conexão entre eles e o ganho viabilizado pelo projeto, no crescimento intelectual e nas for- 
mas de quebrar paradigmas sociais. Por isso, a aprendizagem significativa, tem um papel recorrente, quando possibilita ao indivíduo ter acesso a novos conhecimentos relacionando-os com os anteriores. Contudo, nesta mesma teoria destaca-se que não precisa ser considerada isoladamente, porque as concepções interacionistas e construtivistas serão significativas, desde que atinjam seus objetivos.

Essa (re)construção do conhecimento tornou a avaliação prévia uma precursora das atividades propostas aos alunos. O Quadro 4 demonstra uma pequena quantidade de respostas favoráveis e subtende-se a falta de conhecimento sobre polímeros de uma gama expressiva dos discentes.

Quadro 4: - Quantitativo de respostas corretas.

\begin{tabular}{|c|c|c|c|}
\hline & \multicolumn{2}{|c|}{ Acertos } & \multirow[b]{2}{*}{$\begin{array}{l}\text { Total de } \\
\text { Alunos }\end{array}$} \\
\hline QUESTÕES & $3^{\circ}$ ano B & $3^{\circ}$ ano $\mathrm{C}$ & \\
\hline $1^{\circ}$ & 2 & 3 & 5 \\
\hline $2^{\circ}$ & 3 & 1 & 4 \\
\hline $3^{\circ}$ & 1 & 1 & 2 \\
\hline $4^{\circ}$ & 1 & 1 & 2 \\
\hline Total: & 7 & 6 & 13 \\
\hline
\end{tabular}

Fonte: Elaboração Própria.

Como podemos observar no Quadro 4, apenas 7 alunos do "3" ano B" souberam responder alguma (s) da (s) questão (ões) levantadas no questionário. Já o "3” ano C" tiveram cerca de 6 alunos. Dessa forma, 13 dos 50 alunos avaliados tiveram a habilidade/conhecimento prévio acerca do tema polímeros, representando $26 \%$ do total de alunos participantes. A primeira e a terceira questões foram as mais acertadas, porém por um número de pessoas abaixo do razoável. Demonstrando, mais uma vez, a precariedade dos conhecimentos não só do tema central discutido, mas de outros assuntos transversais.

Vale ressaltar que 20 alunos tentaram responder as questões, mas estas fugiam ao conceito correto e 17 alunos responderam: "não sei” em todas as perguntas. Claramente, podemos atestar a ausência parcial ou total dos conhecimentos da maioria.

A aplicação do jogo despertou nos alunos um grande interesse e curiosidade sobre os polímeros e como ocorriam os processos de polimerização. Isso foi comprovado através de depoimentos dos próprios alunos. Foram destacadas algumas opiniões: Aluno (a) 7: "Gostei bastante do Jogo, ele me fez aprender e me ajudou a entender melhor a aula"; Aluno (a) 15: "Representou para mim uma maneira legal de aprender brincando"; Aluno (a) 28:"Esse jogo desperta a curiosidade e a vontade de aprender"; Aluno (a) 35: As reações foram simples e não precisamos decorá-las".

Durante a aplicação do jogo, percebeu-se a interação, a participação e a autonomia dos alunos para responder de forma reflexiva alguns questionamentos levantados durante a realização do mesmo. Verificou-se ainda respostas bastante consistentes.

Segundo Campos (2005), o jogo tem por funcionalidade viabilizar a aprendizagem, o saber, o conhecimento ea compreensão de mundo. E cabe ao professor, utilizá-lo como ferramenta de exploração e busca de um novo conhecimento. Neste âmbito, pode-se ou não, gerar o interesse, a curiosidade e a motivação dos indivíduos envolvidos.

A Figura 3 menciona a avaliação final aplicada nas duas turmas, exemplificando as respostas dadas por um dos alunos, cujo desempenho atingiu o maior número de acertos.

De acordo com os dados coletados nas duas turmas, na avaliação final, pode-se observar nitidamente a citação acima sendo reafirmada. Os alunos, cuja a turma foi aplicada o jogo tiveram um melhor desempenho se comparado com a outra.

$\mathrm{Na}$ Figura 4, temos dois gráficos demonstrando a porcentagem de alunos que obtiveram acertos com relação ao quantitativo de questões. Observa-se que o número máximo atingido de assertivas corresponde a 4 (quatro). Assim, nenhum dos participes chegou a marca de 6 (seis) acertos.

Vale salientar o gráfico da primeira turma descrita, onde o jogo em questão foi utilizado. Em média $61 \%$ do total, acertou 4 (quatro) indagações, contabilizando pouco mais que a metade da turma. Enquanto no outro gráfico tem-se apenas 3\%, demonstrando um déficit de pessoas bastante grande.

Além disso, 5\% da turma de $3^{\circ}$ ano "B" não conseguiu gabaritar nenhuma das perguntas, em contrapartida no $3^{\circ}$ ano "C" $20 \%$ se mostrou nesta mesma fatia do gráfico.

Finalmente, verificou-se a importância da utilização de novas práticas pedagógicas, em especial de jogos lúdicos, que estimulam os alunos a construir seus conhecimentos de forma dinâmica, interativa e prazerosa. Aulas teóricas junto com o(s) jogo(s) podem contribuir fatidicamente com o aprendizado, aproximando os conceitos ensinados nas aulas teóricas de polímeros e compreendendo melhor a vida, bem como sua relação com a ciência.

A experiência de aprendizado e a significação deste, passam a ser atuantes na formação do educando. O processo de ensino-aprendizagem centraliza-se, à medida que o professor é mediador de ambientes favoráveis ao 


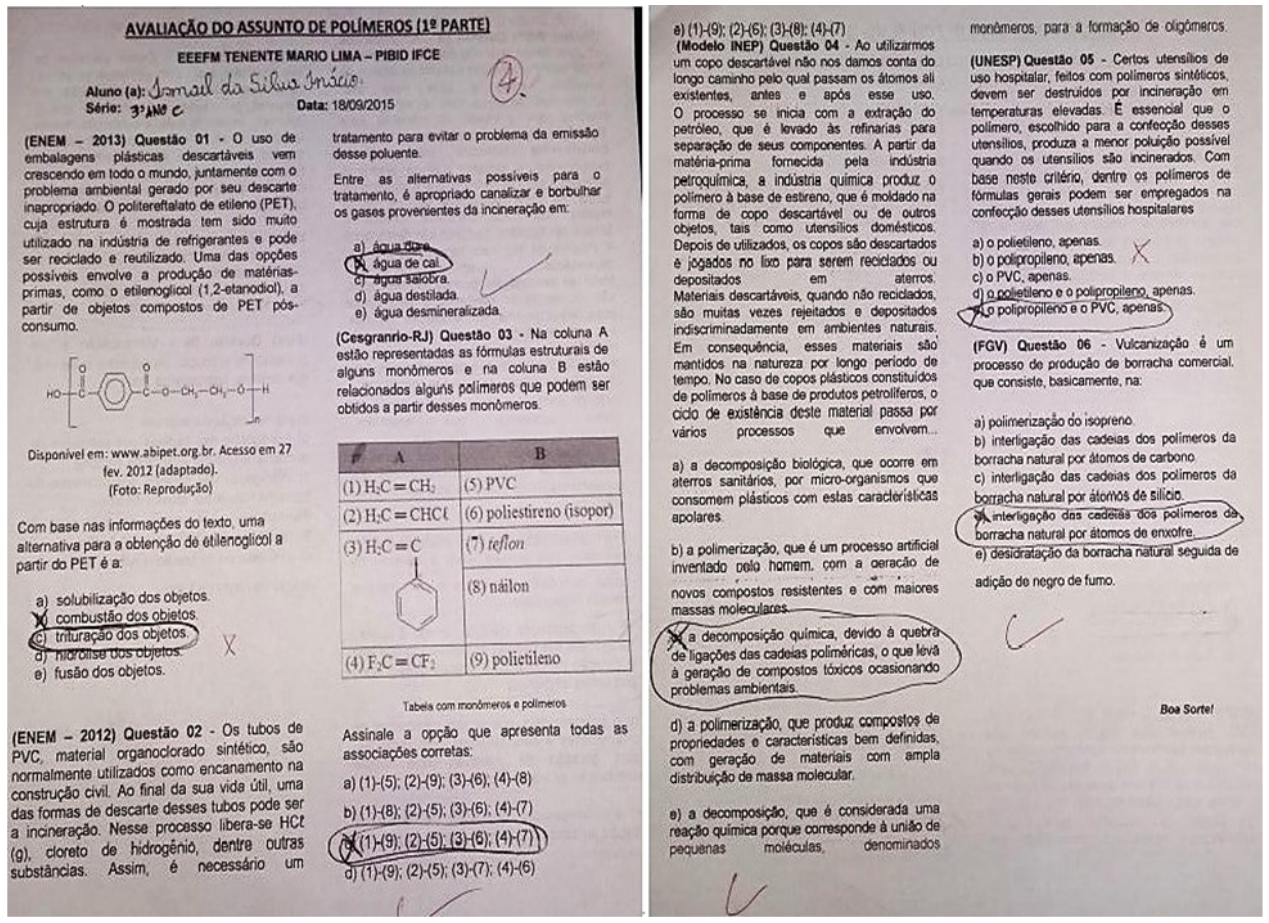

Figura 3: Avaliação Final. Fonte: Elaboração Própria.
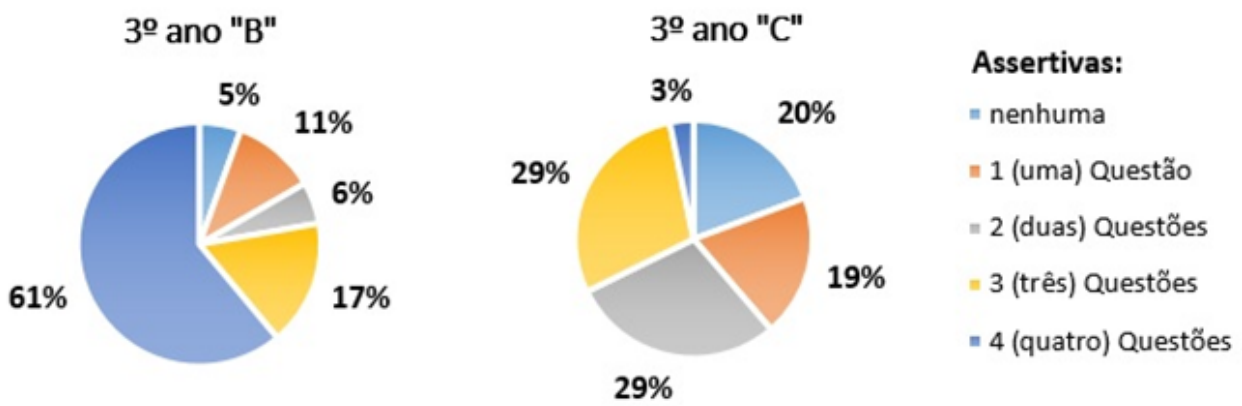

Figura 4: Gráficos da Avaliação Final. Fonte: Elaboração Própria. 
raciocínio científico, através das interações estabelecidas em sala de aula.

\section{CONSIDERAÇÕES FINAIS}

O processo de aprendizagem se realiza através do relacionamento interpessoal entre o aluno e professor, para que isso ocorra é necessária uma boa comunicação de ambas as partes, isso feito continuamente produzirá meios para o desenvolvimento crítico e humano do aluno. O ensinar se define em função do aprender para isso o professor deve estar disposto para designar tal ofício. Um professor que demonstra ter bom ânimo em sala de aula, transmite para os alunos confiança e motivação para aprender.

Com essa pesquisa, podemos averiguar a experiência do que ocorre com atividades lúdicas de ensino, utilizadas nas aulas convencionais. Com resultados satisfatórios ou não, é de suma importância a adoção de novos métodos de ensino pelo professor. Este incentivo leva os discentes a estudar e proporciona interesse, isso é facilmente comprovado pela prática exposta nesse artigo.

A interação e o mutualismo são marcas fortes a serem ressaltadas neste jogo, denunciando a prática indiscriminada de teorização e sistematização do conhecimento. Portanto, a diferenciação é necessária para estabelecer um ensino de Química eficaz e dinâmico.

\section{REFERÊNCIAS}

AUSUBEL, D. P. A aprendizagem significativa: a teoria de David Ausubel. São Paulo: Moraes, 1982.

BERNADELLI, S. Acompanhamento tutorial: Uma proposta para o ensino médio de química. In: BERNADELI, S. (Ed.). Anais do XIX Encontro Regional da Sociedade Brasileira de Química. Ouro Preto: [s.n.], 2005. Cd-Rom.

CAMPOS, D. A. A importância do lúdico na construção dos conceitos matemáticos. Dissertação (Mestrado) - Curso de Pós-graduação em ensino de ciências e matemática. CEFET, Rio de Janeiro, 2005. Disponível em: <http://www.dominiopublico.gov.br/ pesquisa/DetalheObraForm.do?select_action=\&co_ obra=61816> Acesso em: 29 nov. 2015.

GUERREIRO, L. I.; SOUZA, R. K. A.; AMARAL, M. M. A.; FREITAS, S. Z. M.; DUARTE, S. A. R. Projeto sabão "comciência": Fabricação de um sabão ecologicamente correto a partir do óleo de fritura como ferramenta de ensino para a química e educação ambiental. In: Formação de Professores:
As experiências de iniciação à docência no IFCE. Fortaleza: Edições UFC, 2012.

MOREIRA, R. P. Psicologia da Educação: Interação e identidade. 2. ed. São Paulo: FTD, 1996. Coleção Aprender e Ensinar.

PARASURAMAN, A. Marketing research. 2. ed. [S.1.]: Addison Wesley Publishing Company, 1991.

RIBEIRO, A. M. Curso de formação profissional em educação infantil. Rio de Janeiro: EPSJV/Creche Fiocruz, 2005.

SMOLE, K. C. S.; ROCHA, G. H.; CÂNDIDO, P. T.; STANCANELLI, R. Era uma vez na matemática: uma conexão com a literatura infantil. São Paulo: CAEM/IME/USP, 2004.

VYGOTSKY, L. S. A formação social da mente. 7. ed. São Paulo: Martins Fontes, 2008. Original em Russo. Tradução do Grupo de Desenvolvimento e Ritmos Biológicos.

ZANON, D. A. V.; GUERREIRO, M. A. S.;

OLIVEIRA, R. C. O. Jogo didático ludo químico para o ensino de nomenclatura dos compostos orgânico: projeto, produção, aplicação e avaliação. Revista Ciências e Cognição, v. 13, n. 1, p. 72 - 81, 2008. 